\title{
Generation of Constitutive Active ERK Mutants as Tools for Cancer Research in Zebrafish
}

\author{
Hanan Rian, S. F. Gabriel Krens, Herman P. Spaink, and B. Ewa Snaar-Jagalska \\ Institute of Biology, Leiden University, Einsteinweg 55, 2333 CC Leiden, The Netherlands \\ Correspondence should be addressed to B. Ewa Snaar-Jagalska; b.e.snaar-jagalska@biology.leidenuniv.nl
}

Received 26 August 2013; Accepted 26 September 2013

Academic Editors: J.-F. Bodart, R. Hurta, and P. Storz

Copyright (C) 2013 Hanan Rian et al. This is an open access article distributed under the Creative Commons Attribution License, which permits unrestricted use, distribution, and reproduction in any medium, provided the original work is properly cited.

The extracellular-signal-regulated-kinase (ERK) signaling pathway is essential for vertebrate development and is frequently deregulated in human and zebrafish tumors. Previously, we cloned and characterized the zebrafish MAPK gene family and showed that ERK2 is crucial for cell migration and early zebrafish embryogenesis. To further study ERK2 function we generated constitutively active mutant forms of the ERK proteins by introducing conserved point mutations. We validated the enhanced protein activity in vitro by transfection of constructs into zebrafish fibroblast (zf4) cells and demonstrated elevated phosphorylation levels of downstream targets P90RSK and CREB, by ERK2 $2^{\mathrm{L} 84 \mathrm{P} / \mathrm{S} 162 \mathrm{D}}$ and ERK2 $2^{\mathrm{L} 84 \mathrm{P} / \mathrm{S} 162 \mathrm{D} / \mathrm{D} 330 \mathrm{~N}}$ specifically. In vivo validation was performed by ectopic expression of corresponding mRNAs in the transgenic zebrafish FGF-ERK2 reporter fish line $\mathrm{Tg}$ (Dusp6:d2EGFP). Both mutant ERK2 isoforms induced elevated transgene expression compared to ERK2 ${ }^{\mathrm{WT}}$, confirming increased kinase activity in vivo. Phospho-kinomic analysis on peptide microarrays was performed to identify new targets in embryos injected with FGF8 or ERK2 $2^{\mathrm{L} 84 \mathrm{P} / \mathrm{S162D} / \mathrm{D} 330 \mathrm{~N}}$ mRNAs. We detected both FGF8 specific and common signalling targets. Interestingly, with both mRNAs we found increased phosphorylation levels of CDK1, which is critical for proper G2/M phase transition and mitotic entry in proliferation control. These results corroborate that constitutive activation of the ERK2 pathway leads to enhanced, possibly oncogenic, proliferation.

\section{Introduction}

The mitogen-activated protein (MAP) kinases extracellular signal-regulated kinases 1 and 2 (ERK1 and ERK2) are crucial components of the regulatory machinery underlying normal and malignant cell proliferation. The rat sarcoma (RAS)/rapidly accelerated fibrosarcoma (RAF)/MAPK kinase $(\mathrm{MEK} 1 / 2) / \mathrm{ERK} 1 / 2$ oncogenic pathway is induced by various growth factors and forms a convergence point of multiple signaling pathways to control essential cellular processes including migration, differentiation, growth, and survival [1-5]. Approximately, $30 \%$ of all human cancers display evidence of enhanced activation of the RAS/RAF/MEK MAPK pathway [6]. This pathway has been extensively studied in relation to tumor formation and this was greatly facilitated by the availability of constitutively active forms of RAS, RAF, and MEK [7, 8]. Expression of oncogenic RAS as well as constitutive active forms of RAF, and MEK can lead to induced tumorigenic transformation of NIH 3T3 cells $[9,10]$. In addition, in vivo studies with transgenic mice models, expressing constitutive active MEK in the heart, lens chondrocytes, or skin, displayed increased cell numbers or cell size and a delayed onset of cell differentiation [11].

Melanoma is a form of cancer with an extremely high frequency of deregulated RAF/MEK/ERK as $70 \%$ of the melanoma cases harbour increasing activity mutations in the RAF oncogene [12]. The activating mutation in B-RAF (BRAFV600E) found in human nevi drives generation of nevi in zebrafish when expressed in melanocytes. Coupled with the loss of the tumor-suppressor gene P53, nevi progress from benign clusters of melanocytes to malignant melanoma [13, 14]. This indicates that pathology and molecular mechanisms of tumor formation between humans and zebrafish are similar. In addition, providing molecular tools for establishing zebrafish cancer models proved to be valuable for a better understanding of pathogenesis [15-19]. 
TABLE 1: Primer list for site-directed mutagenesis.

\begin{tabular}{cccc}
\hline & Description & Sequence $\left(5^{\prime}>3^{\prime}\right)$ & Reference \\
\hline & ERK2/L84P_fw & CTGCGTGAGATTAAATCCCGCTCCGCTTCAAGC & \\
& ERK2/L84P_rv & GCTTGAAGCGGAGCGGGATTTTAATCTCACGCAG & \\
MAPK1/ERK2 & ERK2/S162D_fw & CGAGACCTGAAGCCAGACAACCTGTTGCTCAACAC & RefSeq: NM_182888 \\
& ERK2/S162D_rv & GTGTTGAGCAACAGGTTGTCTGGCTTCAGGTCTCG & \\
& ERK2/D330N_fw & CCTGGAGCAGTACTATGATCCTACAAATGAGCCTGTTGCTGAG & \\
& ERK2/D330N_rv & CTCAGCAACAGGCTCATTTGTAGGATCATAGTACTGCTCCAGG & RefSeq: NM_201507 \\
& ERK1/L106P_fw & CTGAGAGAGATCAAAATCCCCCTGCGGTTCCATC & \\
& ERK1/L106P_rv & GATGGAACCGCAGGGGGATTTTGATCTCTCTCAG & \\
& ERK1/S184D_fw & CAGAGACCTGAAGCCCGACAACCTTCTCATCAACAC & \\
& ERK1/S184D_rv & GTGTTGATGAGAAGGTTGTCGGGCTTCAGGTCTCTG & \\
& ERK1/D352N_fw & GCAGTACTATGACCCATCTAATGAGCCGGTAGCTGAGGAAC \\
& ERK1/D352N_rv & GTTCCTCAGCTACCGGCTCATTAGATGGGTCATAGTACTGC \\
\hline
\end{tabular}

The same signaling pathways that orchestrate embryonic development are frequently deregulated during tumor progression. In fact, these signaling pathways appear to add significantly to the aggressiveness of tumors. Proteins critical in embryogenesis can be reactivated in adult cells and play a role in allowing tumor cells to overcome barriers and to metastasize [20-22]. Recent studies in our laboratory have demonstrated that depletion of ERK2 in zebrafish disturbs cell migration mechanisms and causes developmental arrest in an early embryonic (blastula) stage. Although the apparent ERK1/2 gene expression levels appear to be constant during all stages of early zebrafish development, differences in ERK1/2 signal activity is first detected with whole mount immunohistochemistry in the enveloping layer (EVL) of the early blastula [23]. During epiboly ERK1/2 activity is induced at the margin by fibroblast growth factor (FGF) morphogens and controls convergent extension cell movements and mesoderm differentiation [23].

We expect that overactivation of ERK2 will increase the proliferation and migration properties of cells in the developing embryo, leading to aberrant developmental program and perhaps tumor formation. In this study, we aim to focus on the ERK/MAPK level of the oncogenic RAS/RAF/MEK/ERK cascade by constructing zebrafish constitutive active mutants that are independent of negative feedback signaling. These tools will be used to understand the downstream molecular mechanisms that are involved in developmental processes, which also play a role in converting normal to uncontrolled cell proliferation. The results illustrate that zebrafish is a powerful vertebrate model that allows simultaneous study of embryonic development and tumor progression using multidisciplinary approaches.

\section{Material and Methods}

2.1. Site-Directed Mutagenesis. The amino acid substitutions were generated in zERK1 and zERK2 by site-directed mutagenesis using the QuikChange(R) site-directed mutagenesis kit (Stratagene). Primers (Sigma-Aldrich) were designed according to the guidelines of the supplied protocol and used for the mutagenesis reaction (Table 1). A forward and reverse primer is designed for each mutation. The primers (forward and reverse) overlap the mutation and have minimal 10 residues at each side of the mutation. The nucleotides complementary to the mutation site are changed to generate the desired substitutions. The four reaction steps of the site-directed mutagenesis kit were performed with 10 ng PCS2+zERK1 or PCS2+zERK2 DNA. Double and triple mutants were generated by repeating the four steps of the mutagenesis reaction with the single and double mutant DNA templates, respectively. The Leucine to Proline substitution was generated by replacing CTC with a CCC codon in ERK1 and CTG with CCG in ERK2, the Serine to Aspartic acid substitution by replacing the TCA with GAC in both ERK1 and ERK2. Finally, the Aspartic acid to Asparagine substitution was obtained by GAT to AAT replacement in zERK1 and zERK2. Importantly, no residues other than the one of interest were found mutated. Sequencing analysis confirmed the successful introduction of all mutations. Importantly, no other residues than the one of interest were found mutated.

2.2. Transfection of PCS $2+E R K 1 / 2$ (mut) in zf4 Cells. The transfection experiments were performed with the FuGene HD transfection reagent (Roche). A transfection mix containing $1.5 \mu \mathrm{g}$ construct DNA, the FuGene reagents, and plain medium (without FCS) was applied to a confluent layer of cells in $0.5 \mathrm{~mL}$ medium and incubated for $6 \mathrm{~h}$. To allow the cells to recover $1.0 \mathrm{~mL}$ medium with FCS was added for overnight incubation. PCS2+ERK1 and PCS2+ERK2 (mutated) constructs were transfected in zf4 cells and after recovery starved for 6.5 hours. The protein was isolated directly after starvation in $1 X$ SDS sample buffer (Red Loading Buffer Pack 1723 Cell Signaling Technology).

2.3. $m$ RNA Synthesis. The PCS2+ERK2_WT PCS2+ERK2* $\mathrm{PCS}_{2}+\mathrm{ERK} 2{ }^{* *}$ and PCS2+ERK2 ${ }^{* * *}$ constructs were linearized with Apal prior mRNA synthesis with the mMessage mMachine kit (Ambion). $1 \mu \mathrm{g}$ of the purified digest was used for the mRNA synthesis reaction with Sp6 RNA 
TABLE 2: MAPK activating mutations.

\begin{tabular}{|c|c|c|c|c|c|}
\hline Organism & Gene name & \multicolumn{3}{|c|}{ Activating mutations } & \multirow{2}{*}{$\begin{array}{c}\text { Reference } \\
\text { Emrick et al. } 2001 \text { [24] }\end{array}$} \\
\hline Rat & rERK2/MAPK1 & L73P & S151D & $\mathrm{D} 319 \mathrm{~N}$ & \\
\hline Yeast & FUS3 & L63P & & $\mathrm{D} 317 \mathrm{~N}$ & Hall et al. 1996 [25] \\
\hline Drosophila & rolled $(\mathrm{rl})$ & & & $\mathrm{D} 334 \mathrm{~N}$ & Brunner et al. 1994 [26] \\
\hline \multirow{2}{*}{ Zebrafish } & zMAPK3/ERK1 & L106P* & S184D $D^{* *}$ & $\mathrm{D} 352 \mathrm{~N}^{* * *}$ & \\
\hline & zMAPK1/ERK2 & L84P* & S162D** & $\mathrm{D} 330 \mathrm{~N}^{* * *}$ & \\
\hline
\end{tabular}

${ }^{*}$ Single mutant, containing L to $\mathrm{P}$ substitution.

** Double mutant, containing L to P and S to D substitutions.

${ }^{* * *}$ Triple mutants, containing $\mathrm{L}$ to $\mathrm{P}$ and $\mathrm{S}$ to $\mathrm{D}$ and $\mathrm{D}$ to $\mathrm{N}$ substitutions.

polymerase. Subsequently, $1 \mu \mathrm{l}$ of DNAse was added to the reaction which is incubated for $30 \mathrm{~min}$ at $37^{\circ} \mathrm{C}$. The mRNA samples were purified with the NucleoSpin RNA Clean-up kit (Nucleobond) and analysed by electrophoresis on a $1 \%$ RNAse-free agarose gel.

2.4. Microinjection in Zebrafish Embryos. $1.0 \mathrm{~nL}$ ERK (mutant) mRNA (50 ng/ $\mu \mathrm{l}$ ) was injected into one-cell stage $\mathrm{Tg}$ (Dusp6:d2EGFP) zebrafish embryos. Injected embryos were used for protein isolation at 5 hours after fertilization (hpf), imaged with LEICA MZ12, or analyzed with COPAS XL from Union Biometrica.

2.5. Protein Isolation from Zebrafish Embryos. Injected embryos of $5 \mathrm{hpf}$ were mechanically dechorionated and kept until protein isolation in agarose coated wells filled with 1X Danieau buffer. For isolation embryos were disrupted in $\mathrm{Ca}^{2+} / \mathrm{Mg}^{2+}$ free solution and cells were subsequently washed with PBS. $1 \mu \mathrm{L} / \mathrm{embryos}$ of $1 \mathrm{X}$ lysis buffer (1M Tris-Hcl pH7.4, $0.5 \mathrm{M}$ EDTA, 1 tablet protease inhibitor, $0.1 \mathrm{M} \mathrm{Na}_{3} \mathrm{VO}_{4}, 0.5 \mathrm{M}$ $\mathrm{NaF}$ ) was added. 2 ug protein from zebrafish embryos was used for western blotting.

2.6. Western Blotting. Protein samples were loaded on a $10 \%$ acrylamide PAGE gel. The high range rainbow molecular weight marker (RPN756 V, Amersham Biosciences) was used for band size determination. After blotting on a nitrocellulose membrane, the blot was incubated with 1:1000 diluted Phospho-p90RSK Thr573 (9346), Phosphop44/42 MAP Kinase Thr202/Tyr204 (9101), p44/42 MAP Kinase (9102), Phospho-Elk-1 Ser383 (9181), Phospho-CREB Ser133 (9198), and phospho-p90RSK Ser380 (9341) rabbit antibody (Cell Signaling technology). The ECL western blotting detection reagents and analysis system (Amersham Biosciences) was used for chemoluminescence detection with secondary antibody, the ECL-HRP Linked Anti-rabbit IgG (Amersham). The blots were stripped with Western-Re-Probe Reagent (G-Biosciences) for restaining.

2.7. Serine Threonine Kinome Profiling. Protein samples were prepared as described previously except that M-PER lysis buffer with phosphatase and protease inhibitors (PIERCE) was used. Samples were snapfreezed in liquid nitrogen and delivered to PamGene International BV for analysis. $1 \mu \mathrm{g}$ of each lysate was loaded on PamChip arrays, with 144 immobilized peptide substrates in a porous ceramic membrane, and incubated in the presence of $400 \mu \mathrm{L}$ ATP. Functional readout is based on kinetic measurement of Ser/Thr phosphorylation occurring on the array using fluorescently labelled anti-phospho-antibodies. Data processing including image quantification, quality control, statistical analysis, and visualization was performed using the Bionavigator software.

\section{Results}

3.1. Conserved Constitutive Activating Mutation Sites in ERK2 Orthologues over Different Evolutionary Phyla. Previous large-scale mutation screens of the Drosophila melanogaster gene rolled and Saccharomyces cerevisiae gene fus3 have facilitated the construction of the constitutive active rat orthologue ERK2 [24]. Three point mutations (L73P, S151D, and $\mathrm{D} 319 \mathrm{~N}$ ) were found to increase the kinase activity a 100 -fold compared to the wild-type rERK2 when introduced simultaneously. In addition, Emrick et al. demonstrates, with an in vitro test were the rates of phosphoryl transfer from [-32P] ATP to myelin basic protein were measured in $10 \mathrm{~min}$ assays, that the L73P/S151D ERK2 double mutant was 50-fold more active. The mutations enhance ERK2 activity most likely by facilitating intramolecular autophosphorylation predominantly at Tyr-185 and to a lesser extent at Thr-183. As in the wild type, phosphorylation at both sites is required for full activation of ERK2 [24]. Considering the high conservation of MAPKs in vertebrates, these point mutations could possibly activate the zebrafish orthologue of rat ERK2 and since ERK1 and ERK2 are 90\% identical the same mutations may also activate zERK1. Multiple alignment including the amino acid sequence of FUS3, ROLLED, rat ERK2, and zebrafish ERK1 and ERK2 showed an evolutionary conservation of the L73P, S151D, and D319N mutation sites (Table 2) [24-26]. The homology model illustrates positions of these conserved sites in zebrafish ERK2 molecule (Figure 1).

The mutations that were found to activate rERK2 were introduced into pCS2+zERK1 and pCS2+zERK2 constructs by site-directed mutagenesis. To determine whether single mutation or a combination of two or three mutations would increase zERK activity we constructed single, double, and triple mutants of both zERK1 and zERK2. Altogether, six 


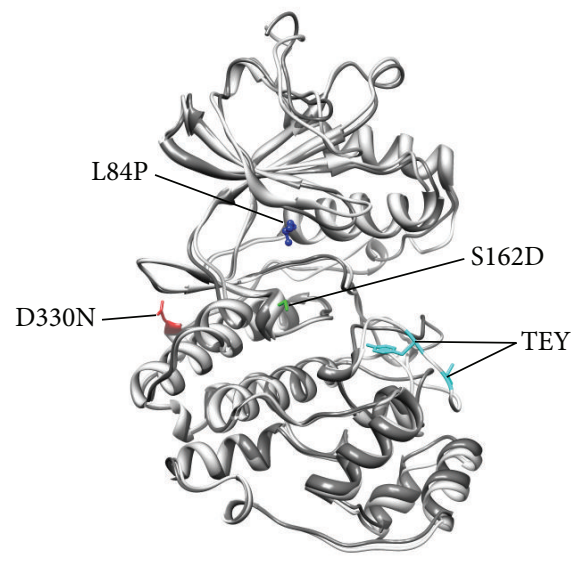

FIGURE 1: Overlap of homology predicted protein models showing the active (grey) and inactive (white) zebrafish ERK2 protein structure. Phosphorylation of the dual phosphorylation site (TEY) causes structural rearrangement of the activation lip. The substitutions may cause rearrangements of intermolecular interactions between amino acids resulting in a smaller distance between the activation lip with the TEY motif and the catalytic site and facilitating autophosphorylation. The L83P site (blue) is located in $\alpha$-helix C and S162D (green) in the catalytic loop, both in the active site of the kinase. The D330N (red) mutation is located in the CD-site which is a docking site for inhibitory phosphatases. The D330N substitution prevents ERK inhibitory phosphatases to bind. The atomic resolution models of zebrafish ERK2 were constructed with the zERK2 amino acid sequence (ENSAMBLE:ENSDARP00000038550) and based on three-dimensional X-ray crystallography predictions PDB:1ERK and PDB:2ERK (phosphorylated). Homology modelling was performed using free online Swiss model and models were illustrated with Chimera.

potential constitutive active ERK mutants were obtained: zERK1 $1^{\mathrm{L} 106 \mathrm{P}}, \quad \mathrm{zERK} 1^{\mathrm{L} 106 \mathrm{P} / \mathrm{S} 184 \mathrm{D}}, \quad \mathrm{zERK} 1^{\mathrm{L} 106 \mathrm{P} / \mathrm{S} 184 \mathrm{D} / \mathrm{D} 352 \mathrm{~N}}$, zERK2 ${ }^{\mathrm{L} 84 \mathrm{P}}, \mathrm{zERK} 2^{\mathrm{L} 84 \mathrm{P} / \mathrm{S} 162 \mathrm{D}}$, and $z E R K 2^{\mathrm{L} 84 \mathrm{P} / \mathrm{S} 162 \mathrm{D} / \mathrm{D} 330 \mathrm{~N}}$.

3.2. Erk2 Double and Triple Mutants Phosphorylate Downstream Targets In Vitro Despite Growth Factor Deprivation. To compare the activity of ERK mutants and wild-type (wt) proteins we performed a biochemical characterization experiment after transfection of corresponding plasmids into cultured zebrafish fibroblast (zf4) cells (Figure 2). The transfected cells were starved for $6.5 \mathrm{~h}$ in cell culture medium without FCS before protein isolation. Since the MAPK/ERK pathway is known to be induced by growth factors, we expected the activity of endogenous and ectopic ERK to be decreased to basal levels by starvation, enabling us to compare downstream signalling between wt and mutant ERK proteins. Subsequent western blotting with antibodies against total ERK showed that all transfected zebrafish ERK1 (data not shown) and ERK2 constructs were expressed in zf 4 cells (Figure 2(a)). In addition to the band of endogenous zERK, visible in all samples, a second band was detected in protein samples of ERK1 and ERK2 transfected cells but not in the control untransfected cells and the cells transfected with PCS2+eGFP. The extra bands have the exact molecular mass of the ectopic zERKs which are modified to have a 1.66 and $1.23 \mathrm{kD}$ higher molecular mass than the endogenous zERK1 and zERK2, respectively. The bands of ectopic zERK1 (data not shown) and zERK2 were also visible after detection with antibody against phosphorylated ERK1/2 in samples of the ERK transfected cells. To be able to detect differences in the degree of target phosphorylation between mutant and wildtype zERKs, antibodies against phosphorylated p90 ribosomal S6 kinase (p90RSK), cAMP response element-binding protein (CREB) were used (Figures 2(b)-2(d)). Western blotting quantification and subsequent correction for ectopic ERK synthesis and normalization against wt ERK confirm the increased phosphorylation of the triple mutants of both ERK1 and ERK2. For the detection of phosphorylated p90RSK, two different antibodies were available, which cross reacted with the zebrafish ortholog, directed against distinct sites targeted by ERK. With both antibodies, an increased phosphorylation of p90RSK was found in cells transfected with the double and triple mutants of zERK2 only when compared to cells with wt ERK $1 / 2$ overexpression. In addition, phosphorylation increase of the other ERK target CREB was detected in the zERK2 double and triple mutant samples. No increase of either phosphorylated p90RSK or CREB was detected in cells transfected with wild-type or mutated ERK1 (data not shown).

3.3. CA-ERK2 and FGF8 Induce Transgene Expression of $\operatorname{Tg}($ Dusp6:d2EGFP). Synthesized ERK2 wt and mutant mRNA were injected in 1-cell stage zebrafish embryos for in vivo validation of constitutive activation. Ectopic phosphorylated ERK was detectable in protein samples collected at $5 \mathrm{hpf}$ with western blotting (Figure 3(a)). In addition, the ERK2 triple mutant was significantly more phosphorylated and the double mutant was slightly increased compared to the ectopic wt ERK2 and the ERK2 single mutant. Therefore, we continued the validation of the double and triple ERK2 mutants in vivo, based on an ERK2 negative feedback mechanism, involving the downstream gene target dual specificity phosphatase (DUSP6) in Tg(Dusp6:d2EGFP) (Figure 3(b)). The FGF8 morphogen induces ERK activity at the dorsal site and the margin of the zebrafish embryo during epiboly. Subsequently, ERK2 induces the expression of DUSP6 which is a dual specificity phosphatase that removes both activating phosphates of the ERK2 (Thr-Glu-Tyr) motif [27]. When FGF8 mRNA was injected in Tg(Dusp6:d2EGFP) embryos, the GFP signal increased and shifts from the dorsal site to the entire animal pole (Figure 3(b)). Batches of Tg(Dusp6:d2EGFP) embryos were injected with wt ERK2, ERK2 double mutant, triple mutant, and FGF8 mRNA and analyzed with the COPAS XL which performs large-scale GFP fluorescence detection of live embryos. Both mutants as well as FGF8 increased the eGFP signal in heterozygous $\operatorname{Tg}$ (Dusp6:d2EGFP) embryos at 5 hpf (Figure 3(c)). 


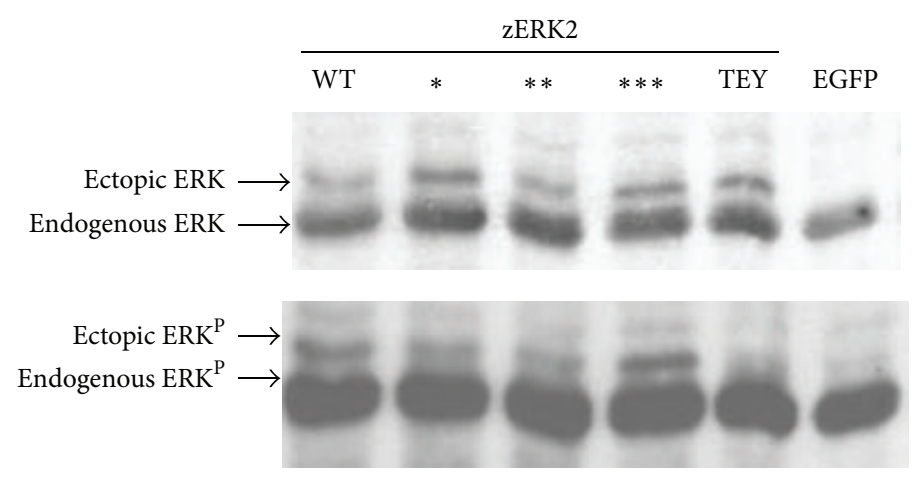

(a)

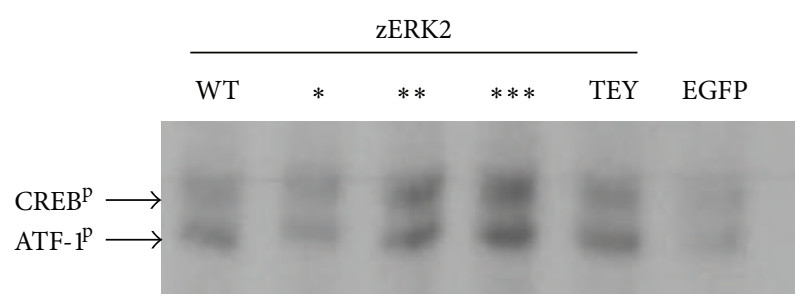

(c)

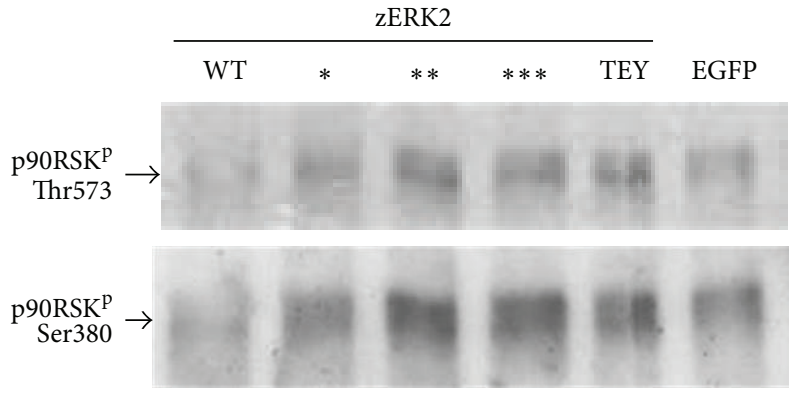

(b)

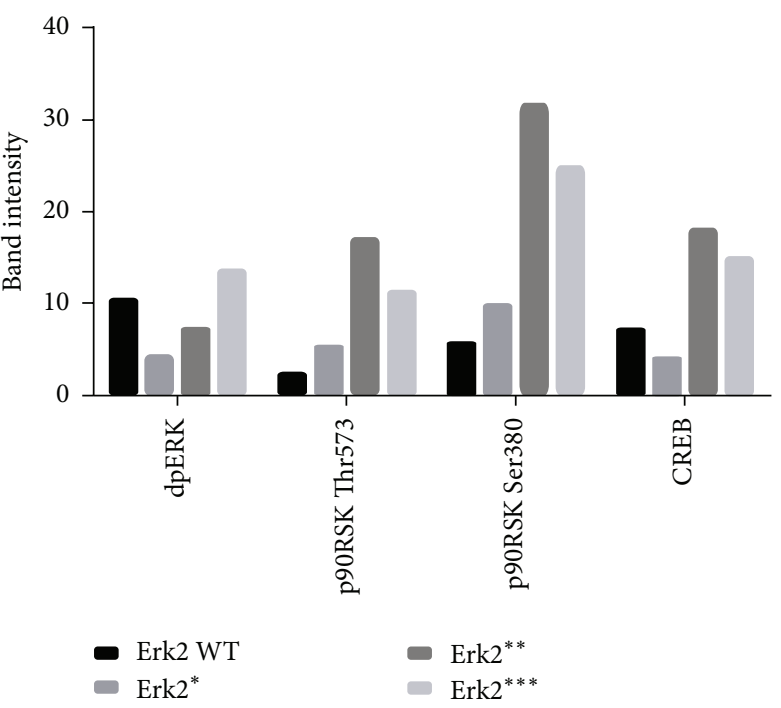

(d)

FIGURE 2: Western blot detection of ERK1/2, P90RSK, and CREB phosphorylation in zf4 cells transfected with PCS2+ERK1 and PCS2+ERK2 (mutated) constructs. (a) Western blotting was performed with total ERK and dpERK. The Ectopic ERKs derived from synthetic mRNAs have a greater MW than the endogenous ERKs, due to the introduction of a small linker, and can therefore be distinguished by size. The bands with higher molecular mass were also detected with anti-ERK $1 / 2$ antibody in cells transfected with ERK ${ }^{\mathrm{TEY}}$ mutants but not with the antiphospho-ERK 1/2 antibody. This confirms that the bands with higher molecular weights are from the transfected ectopic ERK. (b) Western blot detection of phospho-p90Rsk with two different antibodies one targeted against Thr573 and another against Ser380. (c) Western blot detection with the phospho-Creb Ser133 antibody which cross-reacts with phospho-ATF. (d) Band intensities were measured for quantification of western blots ((a)-(c)) dp-ERK(ectopic) p-P90RSK and p-CREB band intensities were corrected for total ectopic ERK synthesis. Mutants were normalized against ERK1-WT or ERK2-WT. WT: protein samples from zf4 cells transfected with wtERK1 or wtERK $2{ }^{*}:$ single mutants $\mathrm{ERK}^{\mathrm{L} 106 \mathrm{P}} \mathrm{ERK}^{\mathrm{L} 84 \mathrm{P}},{ }^{* *}$ : double mutants ERK1 ${ }^{\mathrm{L} 106 \mathrm{P} / \mathrm{S} 184 \mathrm{D}} \mathrm{ERK} 2^{\mathrm{L} 84 \mathrm{P} / \mathrm{D} 162 \mathrm{D}},{ }^{* * *}$ : triple mutants ERK1 ${ }^{\mathrm{L} 106 \mathrm{P} / \mathrm{S} 184 \mathrm{D} / \mathrm{D} 352 \mathrm{~N}} \mathrm{ERK} 2^{\mathrm{L} 84 \mathrm{P} / \mathrm{S} 162 \mathrm{D} / \mathrm{D} 330 \mathrm{~N}}, \mathrm{TEY}$ : ERK1 ${ }^{\text {T216A/Y218A }}$, and ERK2 ${ }^{\text {T194A/Y196A }} 0$ : untransfected zf4 cells, EGFP: zf4 cells transfected with pcs2+EGFP.

3.4. Kinome Profiling Reveals Increased Phosphorylation of the Cell Cycle Progression Protein CDK1 as a Consequence of FGF8 and CA-ERK2 Overexpression in Zebrafish Embryos. To identify substrates that are in particular affected by ERK constitutive activation, we performed a serine threonine phosphokinome peptide array experiment comparing lysates of ERK2 ${ }^{* * *}$, ERKWT, and FGF8 injected embryos against an uninjected control. 111 peptides were phosphorylated by the zebrafish lysates and with model-based clustering 7 clusters were distinguished from this pool (Figure 4). Cluster 1 comprises peptides which are less phosphorylated due to FGF8 overexpression, while cluster 2 is showing the opposite effect of FGF8-specific targets which are increasingly phosphorylated (Tables 3 and 5). Clusters 3 and 4 represent peptides with decreased and increased phosphorylation, respectively, as a result of wt ERK2 overexpression. This might be the effects of negative feedback as a consequence of ERK overexpression that have less or no effect on the mutant. Clusters 5 and 7 are less phosphorylated peptides due to overactivation of the FGFERK pathway or due to injection. Cluster 6 consists of an interesting group of peptides which are increasingly phosphorylated by both FGF8 and the ERK2 ${ }^{* * *}$ mutant (Tables 4 and 6). The proliferation marker CDK1 (CDC2) is found among the cluster 6 peptides of which phosphorylation within amino acids $154-169$ is significantly induced by FGF8 and $\operatorname{ERK}^{* * *}(P$ value $<0.05)$ compared to uninjected embryos. 


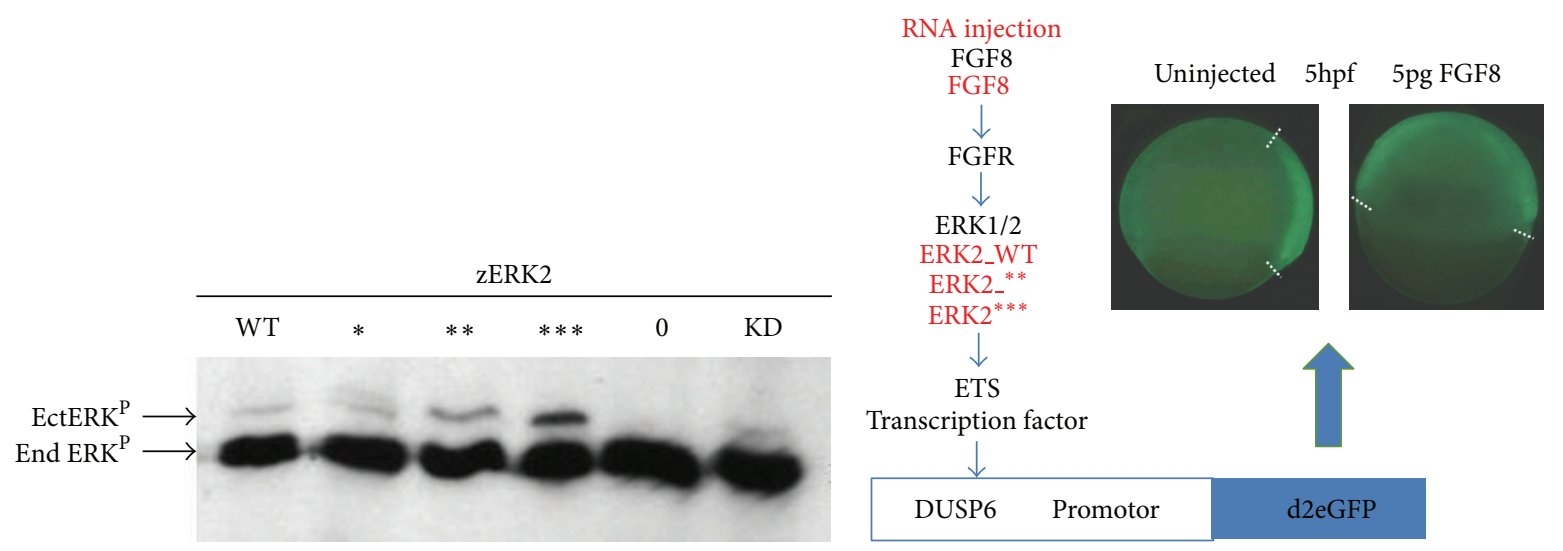

(a)

(b)

COPAS XL

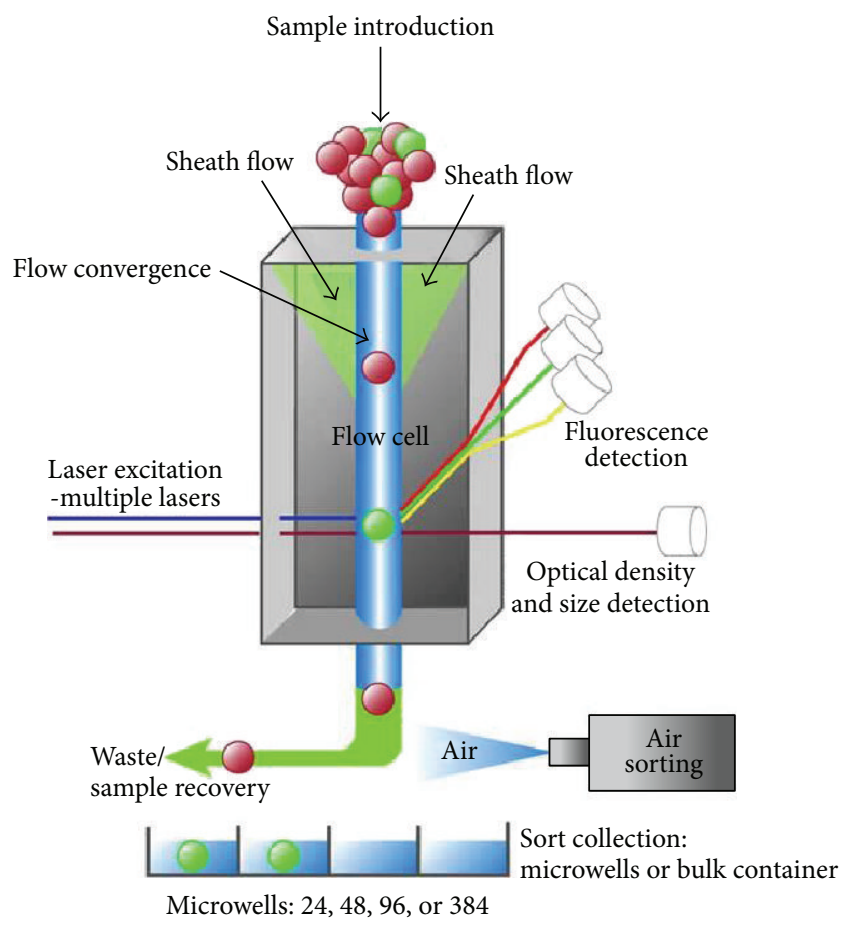

(c)
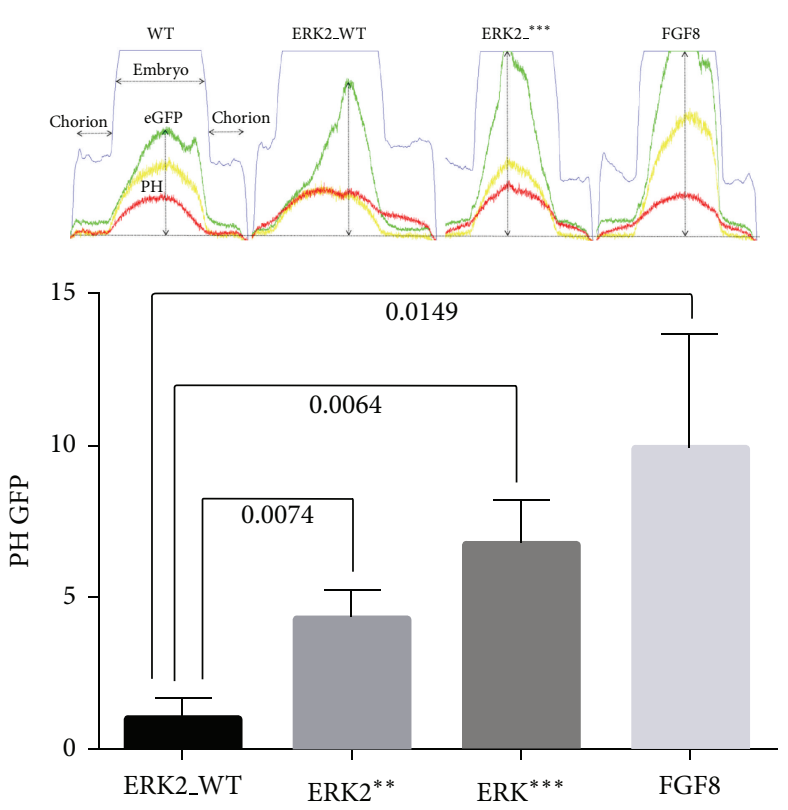

(d)

FIGURE 3: In vivo ERK signaling activity analysis of ectopically expressed FGF or ERK isoforms.(a) western blot detection of dpERK on protein samples isolations from $5 \mathrm{hpf}$ embryos injected with $50 \mathrm{pg}$ WT or mutant ERK2 mRNA and isolated. (b) Flowchart of the experimental procedure using the $\mathrm{Tg}\left(\right.$ Dusp6:d2EGFP) and subsequent COPAS XL $\mathrm{Union}_{\text {Biometrica }}$. analysis (c). $5 \mathrm{hpf}$ old living embryos are passed through the COPAS flowcell and optical density/axial length (blue), GFP (green), YFP (yellow), and dsRED (red) fluorescence profiles are recorded Union Biometrica, Inc. D. Peak height values (PH) of the GFP channel were collected for ERK2_WT, ERK2**, ERK2***, and FGF8 mRNA injected embryos, after corrected for autofluorescence/background of noninjected wild-type embryos (see Section 2), and plotted in a bar graph as the mean value of three biological experiments, each with a minimum of 30 embryos/condition. Mean GFP PH values are normalized against ERK2_WT. Arrow bares represent standard deviations of the means of the three biological experiments; $P$ values were calculated by applying a $t$-test with Welch-correction.

\section{Discussion}

Three point mutations, which already were shown to activate rat ERK2, were sequentially introduced in zERK1 and zERK2 providing us with six mutants to be tested for increased activation [24]. The six mutants include the single mutants $\mathrm{zERK} 1^{\mathrm{L} 106 \mathrm{P}}$ and $\mathrm{zERK} 2^{\mathrm{L} 84 \mathrm{P}}$, the double mutants $z E R K 1^{\mathrm{L} 106 \mathrm{P} / \mathrm{S} 184 \mathrm{D}}$ and $\mathrm{zERK} 2^{\mathrm{L} 84 \mathrm{P} / \mathrm{S} 162 \mathrm{D}}$, and finally the triple mutants zERK1 $1^{\mathrm{L} 106 \mathrm{P} / \mathrm{S} 184 \mathrm{D} / \mathrm{D} 352 \mathrm{~N}}$ and $\mathrm{zERK} 2^{\mathrm{L} 84 \mathrm{P} / \mathrm{S} 162 \mathrm{D} / \mathrm{D} 330 \mathrm{~N}}$. The Western blot results with total and dpERK antibodies showed that all mutants were successfully expressed and phosphorylated in $\mathrm{zf} 4$ cells. In addition, western blot analysis 
TABLE 3: Cluster 2 Peptides with increased phosphorylation specifically by FGF8 samples. Protein samples were prepared at 5 hpf. ANOVA and Dunnett's test are performed with a biological triplicate.

\begin{tabular}{lccccccccc}
\hline \multirow{2}{*}{ Peptide } & \multicolumn{3}{c}{ Fold change (mean 2log values) } & \multicolumn{3}{c}{ P values versus WT } & \multicolumn{3}{c}{ P values versus ERK2_WT } \\
& WT & ERK2WT & ERK2 & FGF8 & ERK2WT & ERK2 ${ }^{* * *}$ & FGF8 & ERK2*** & FGF8 \\
\hline ACM5_494_506 & 1.00 & 0.99 & 1.02 & 1.04 & 0.909 & 0.925 & 0.093 & 0.835 & 0.079 \\
ACM5_498_510 & 1.00 & 0.98 & 1.01 & 1.08 & 0.897 & 0.730 & 0.119 & 0.637 & 0.143 \\
ANDR_785_797 & 1.00 & 0.98 & 1.01 & 1.05 & 0.923 & 0.471 & 0.153 & 0.529 & 0.133 \\
CA2D1_494_506 & 1.00 & 1.05 & 1.06 & 1.10 & 0.290 & 0.364 & $0.012^{\dagger}$ & 0.864 & 0.056 \\
ESR1_160_172 & 1.00 & 0.97 & 0.99 & 1.04 & 0.451 & 0.189 & 0.183 & 0.523 & 0.060 \\
GPR6_349_361 & 1.00 & 0.96 & 1.01 & 1.02 & 0.382 & 0.465 & 0.609 & 0.876 & 0.189 \\
GSUB_61_73 & 1.00 & 0.98 & 0.93 & 1.05 & 0.441 & 0.147 & 0.942 & 0.432 & 0.402 \\
KS6A1_374_386 & 1.00 & 1.00 & 1.02 & 1.09 & 0.969 & 0.822 & 0.430 & 0.852 & 0.409 \\
P53_12_24 & 1.00 & 1.07 & 0.97 & 1.58 & 0.906 & 0.543 & 0.472 & 0.472 & 0.543 \\
\hline
\end{tabular}

${ }^{\dagger} P$ values $<0.05$.

TABLE 4: Cluster 6 peptides are increasingly phosphorylated by FGF8 or ERK2*** but not ERK2WT samples. ANOVA and Dunnett's test are performed with a biological triplicate.

\begin{tabular}{lcccccccccc}
\hline \multirow{2}{*}{ Peptide } & \multicolumn{3}{c}{ Fold change (from mean 2log) } & \multicolumn{3}{c}{ P values versus WT } & \multicolumn{3}{c}{ P values versus ERK2_WT } \\
& WT & ERK2WT & ERK2 ${ }^{* * *}$ & FGF8 & ERK2WT & ERK2 ${ }^{* * *}$ & FGF8 & ERK2 ${ }^{* * *}$ & FGF8 \\
\hline RBL2_655_667 & 1.00 & 0.93 & 1.11 & 1.31 & 0.772 & 0.671 & 0.205 & 0.482 & 0.135 \\
PRKDC_2618_2630 & 1.00 & 0.98 & 1.17 & 1.63 & 0.734 & 0.618 & 0.267 & 0.412 & 0.165 \\
PP2AB_297_309 & 1.00 & 0.88 & 1.11 & 1.27 & 0.270 & 0.307 & 0.510 & 0.058 & 0.104 \\
MBP_222_234 & 1.00 & 0.94 & 1.19 & 1.05 & 0.697 & 0.055 & 0.591 & $0.032^{\dagger}$ & 0.367 \\
NEK3_158_170 & 1.00 & 1.21 & 1.27 & 1.50 & 0.516 & 0.093 & $0.031^{\dagger}$ & 0.240 & 0.080 \\
KCC2G_278_289 & 1.00 & 1.02 & 1.28 & 1.43 & 0.537 & 0.099 & $0.012^{\dagger}$ & $0.040^{\dagger}$ & $0.006^{\dagger}$ \\
CGHB_109_121 & 1.00 & 0.97 & 1.29 & 1.20 & 0.446 & 0.064 & 0.143 & $0.022^{\dagger}$ & $0.047^{\dagger}$ \\
CDC2_154_169 & 1.00 & 0.95 & 1.11 & 1.15 & 0.982 & $0.041^{\dagger}$ & $0.037^{\dagger}$ & $0.042^{\dagger}$ & $0.038^{\dagger}$ \\
\hline
\end{tabular}

${ }^{\dagger} P$ values $<0.05$.

with dp-ERK after transfection of zf4 cells (Figure 2(a)) as well as mRNA injection in zebrafish embryos (Figure 3(a)) clearly showed increased TEY phosphorylation of zERK1 (data not shown) and zERK2 triple mutants. Compared to the wild type isoforms of the proteins showed that the ERK2 double mutant induced a slight increase in signaling to downstream targets, despite the poorly detectable increase of its TEY phosphorylation in transfected zf4 cells. This could have been a detection discrepancy of this assay as the double mutant appears to be indeed more phosphorylated at its dual phosphorylation site in zebrafish embryos (Figure 3(a)). Strikingly, the triple mutant of ERK2 revealed clear hyperphosphorylation of ERK substrates P90RSK and CREB (Figures $2(b)-2(d)$ ). In the absence of growth factor stimulation $\mathrm{zERK} 2^{\mathrm{L} 84 \mathrm{P} / \mathrm{S} 162 \mathrm{D}}$ and $\mathrm{zERK} 2^{\mathrm{L} 84 \mathrm{P} / \mathrm{S} 162 \mathrm{D} / \mathrm{D} 330 \mathrm{~N}}$ maintained activity and phosphorylation of substrates in zf 4 cells. However after 6 hours of starvation phosphorylated endogenous ERK1/2, the high-intensity bands (phospho-ERK1 and phospho-ERK2 combined) on the blot (Figure 2(a)), was still abundantly present in zf4 cells and the question remains how the ectopic ERK2 mutants have caused this increase of P90RSK and CREB phosphorylation. It is possible that the mutations have influenced ERK2 signalling dynamics through affecting its shuttling rate between cytoplasm and nucleus. The cytoplasmic nuclear shuttling rate of ERK2 increased after treatment with fibroblast growth factor (FGF) or epidermal growth factor $[28,29]$.

We continued investigating the constitutive active ERK2 double and triple mutants in heterozygous $\mathrm{Tg}$ (Dusp6:d2EGFP) at $5 \mathrm{hpf}$ and included FGF8 as a positive control. eGFP induction after FGF8 mRNA injection was demonstrated previously by Molina et al. using fluorescent microscopy [30]. We were able to quantify increased eGFP fluorescence in batches of minimal 30 FGF8 mRNA injected embryos with the COPAS XL (Figure 3). During zebrafish epiboly FGF8 acts as a morphogen which induces the MEK/ERK pathway at the margin where it regulates the gene expression of DUSP6 [27]. Therefore, along with FGF8 we injected the ERK2 WT, double, and triple mutants for in vivo quantitative fluorescent detection and conclude that the ERK2 double and triple mutants are more potent to induce downstream gene expression than the WT form. For the next experiment, we proceeded further with the ERK2 triple mutant because the in vivo monitored increase in activity was 
TABLE 5: Cluster 2 gene ontology.

\begin{tabular}{lcc}
\hline Peptide & Name protein & Functions \\
\hline P53_12_24 & $\begin{array}{c}\text { Protein import into nucleus, negative regulation of transcription from RNA } \\
\text { polymerase II promoter, transcription factor activity, embryonic development, } \\
\text { somitogenesis, release of cytochrome c from mitochondria, T cell } \\
\text { proliferation involved in immune response, B/T cell lineage commitment, } \\
\text { Cellular tumor antigen p53. Tumor } \\
\text { suppressor p53. Phosphoprotein } \\
\text { p53. Antigen NY-CO-13 }\end{array}$ & $\begin{array}{c}\text { DN binding chromatin binding, DNA double-strand break repair, apoptotic } \\
\text { process, DNA damage response, ER overload response, cell cycle arrest, Ras } \\
\text { protein signal transduction, multicellular organismal development, } \\
\text { gastrulation, negative regulation of neuroblast proliferation, central nervous } \\
\text { system development, cell aging, blood coagulation, rRNA transcription, X-ray } \\
\text { response, gamma radiation }\end{array}$ \\
\hline
\end{tabular}

Toll-like receptor signaling pathway, cell cycle, synaptic transmission, axon

Ribosomal protein S6 kinase alpha-1.S6K-alpha 1. p90-RSK 1. guidance, negative regulation of apoptotic process, regulation of translation in response to stress, regulation of DNA-dependent transcription in response to stress, innate immune response, cell differentiation positive regulation of KS6A1_374_386 $\quad$ pp90RSK1. p90S6K. RSK-1. transcription from RNA polymerase II promoter, nerve growth factor receptor MAPKAPK1A signaling pathway, stress-activated MAPK cascade

\begin{tabular}{|c|c|c|}
\hline GSUB_61_73 & $\begin{array}{c}\text { G-substrate. C7orf16.protein } \\
\text { phosphatase 1. regulatory subunit } 17 \\
\text { (PPP1R17) }\end{array}$ & Central nervous system development \\
\hline GPR6_349_361 & $\begin{array}{l}\text { Sphingosine 1-phosphate receptor. } \\
\text { G-protein coupled receptor } 6\end{array}$ & G-protein coupled receptor activity \\
\hline ESR1_160_172 & $\begin{array}{c}\text { Estrogen receptor (ER). Estradiol } \\
\text { receptor (ER-alpha). Nuclear } \\
\text { receptor subfamily } 3 \text { group A } \\
\text { member } 1\end{array}$ & $\begin{array}{l}\text { Epithelial cell development, osteoblast development, sequence-specific DNA } \\
\text { binding, transcription factor activity, steroid hormone receptor activity, } \\
\text { DNA-dependent transcription initiation from RNA polymerase II promoter, } \\
\text { beta-catenin binding, transcription factor binding, androgen metabolic } \\
\text { process, chromatin remodeling complex, nitric-oxide synthase regulator, } \\
\text { estrogen receptor signaling pathway, type } 1 \text { metabotropic glutamate receptor } \\
\text { binding, response to estradiol stimulus, regulation of apoptotic }\end{array}$ \\
\hline CA2D1_494_506 & $\begin{array}{l}\text { Voltage-dependent calcium channel } \\
\text { subunit alpha-2/delta-1 precursor. } \\
\text { CACNA2D1 }\end{array}$ & Voltage-gated calcium channel complex, sarcoplasmic reticulum, T-tubule \\
\hline ANDR_785_797 & $\begin{array}{c}\text { Androgen receptor. } \\
\text { Dihydrotestosterone receptor. } \\
\text { Nuclear receptor subfamily } 3 \text { group } \\
\text { C member } 4\end{array}$ & $\begin{array}{l}\text { In utero embryonic development, DNA binding, chromatin binding, } \\
\text { transcription factor activity, androgen receptor activity, sex differentiation, } \\
\text { beta-catenin binding, positive regulation of cell proliferation, male gonad } \\
\text { development, prostate gland development, response to insulin stimulus, } \\
\text { positive regulation of intracellular estrogen receptor signaling pathway, } \\
\text { negative regulation of apoptotic process, positive regulation of MAPK } \\
\text { cascade, positive regulation of insulin-like growth factor receptor signaling } \\
\text { pathway, positive regulation of integrin biosynthetic process, negative } \\
\text { regulation of epithelial cell proliferation, positive regulation of NF-kappaB } \\
\text { transcription factor activity, prostate gland development }\end{array}$ \\
\hline $\begin{array}{l}\text { ACM5_498_510 } \\
\text { ACM5_494_506 }\end{array}$ & $\begin{array}{l}\text { Muscarinic acetylcholine receptor } \\
\text { M5. cholinergic receptor. } \\
\text { muscarinic } 5\end{array}$ & \\
\hline
\end{tabular}

more significant than that of the double mutant. In addition to the two substitutions that facilitate autophosphorylation, the triple mutant contains an extra substitution in the phosphatases interacting motif which prevents inactivation of ERK2 by feedback signaling, resulting in the highest phosphorylation activity level for the triple mutant isoform.

The fibroblast growth factors are known to bind to their corresponding tyrosine kinase receptors and they relay the extracellular signals further to the ERK/MAPK pathway and the PI3/AKT pathway. Therefore, part of FGF downstream signaling should overlap with ERK2 downstream signaling. To identify this pool of substrates in zebrafish cell lysates isolated from 5 hours old embryos, using PamGene serine threonine kinome peptide arrays (Figure 4), kinome profiles of embryos injected with FGF8, wt ERK2, and ERK2 triple mutant mRNA were compared against uninjected wt with model-based clustering. The 7 clusters of peptides were identified of which cluster 6 represents the overlapping pool of peptides induced by FGF8 and ERK2 triple mutant and cluster 2 the FGF8 targets independent of ERK/MAPK 
TABLE 6: Cluster 6 gene ontology.

\begin{tabular}{|c|c|c|}
\hline Peptide & Name protein & Functions \\
\hline RBL2_655_667 & $\begin{array}{l}\text { Retinoblastoma-like protein } \\
\text { 2.p130.PRB2. RBR-2 }\end{array}$ & $\begin{array}{l}\text { Tumor suppressor, inhibitor of E2F-mediated transactivation, cell cycle } \\
\text { regulation and proliferation, differentiation during human placental } \\
\text { development }\end{array}$ \\
\hline PRKDC_2618_2630 & $\begin{array}{l}\text { DNA-dependent protein kinase } \\
\text { catalytic subunit (DNA-PKcs). } \\
\text { DNPK1.p350 }\end{array}$ & $\begin{array}{l}\text { Apoptosis (FAS signaling pathway) Cell Cycle: G2/M Checkpoint, B-cell } \\
\text { differentiation, telomere maintenance, DNA double strand break repair, } \\
\text { transcription factor }\end{array}$ \\
\hline PP2AB_297_309 & $\begin{array}{l}\text { Serine/threonine-protein } \\
\text { phosphatase } 2 \mathrm{~A} \text { catalytic subunit } \\
\text { beta isoform. PP2A-beta. } \\
\text { PPP2CB. PPM1B }\end{array}$ & $\begin{array}{c}\text { Fibroblast growth factor receptor signaling pathway, negative regulation of } \\
\text { Ras protein signal transduction, negative regulation of apoptotic process, } \\
\text { proteasomal ubiquitin-dependent protein catabolic process }\end{array}$ \\
\hline MBP_222_234 & $\begin{array}{l}\text { Myelin basic protein. Myelin A1 } \\
\text { protein. Myelin } \\
\text { membraneencephalitogenic } \\
\text { protein }\end{array}$ & $\begin{array}{l}\text { Protease binding, immune response, synaptic transmission, structural } \\
\text { constituent of myelin sheath }\end{array}$ \\
\hline NEK3_158_170 & $\begin{array}{l}\text { NimA-related protein kinase } 3 . \\
\text { HSPK } 36\end{array}$ & Protein serine/threonine kinase activity, cell cycle, mitosis, cell division \\
\hline KCC2G_278_289 & $\begin{array}{l}\text { Calcium/calmodulin-dependent } \\
\text { protein kinase type II gamma } \\
\text { chain. CaM kinase II subunit } \\
\text { gamma, CaMK-II subunit } \\
\text { gamma. CAMK2G }\end{array}$ & $\begin{array}{l}\text { G1/S transition of mitotic cell cycle, response to hypoxia, synaptic } \\
\text { transmission, cytokine-mediated signaling pathway, insulin secretion }\end{array}$ \\
\hline CGHB_109_121 & $\begin{array}{l}\text { Choriogonadotropin subunit } \\
\text { beta precursor. CGB5. HCG. } \\
\text { CG-beta }\end{array}$ & Hormone-mediated signaling pathway \\
\hline CDC2_154_169 & $\begin{array}{l}\text { Cell division control protein } 2 \\
\text { homolog.p34 protein kinase. } \\
\text { Cyclin-dependent kinase } 1 . \\
\text { CDK1. CDC28A. P34CDC2 }\end{array}$ & $\begin{array}{c}\text { Cell cycle checkpoint, G1/S transition of mitotic cell cycle, MAPK cascade } \\
\text { activation, microtubule cytoskeleton organization, toll-like receptor signaling } \\
\text { pathway, cyclin-dependent protein kinase activity, spindle microtubule, DNA } \\
\text { replication, DNA repair protein complex assembly, apoptotic process, DNA } \\
\text { damage checkpoint, epidermal growth factor receptor signaling pathway, Ras } \\
\text { protein signal transduction, pronuclear fusion, axon guidance, cell aging, } \\
\text { insulin receptor signaling pathway, RNA polymerase II carboxy-terminal } \\
\text { domain kinase activity, fibroblast growth factor receptor signaling pathway, } \\
\text { gene expression, regulation of Schwann cell }\end{array}$ \\
\hline
\end{tabular}

signaling. However, the fold induction of phosphorylation of each peptide compared to the uninjected control was quite low and often did not exceed the variation between the biological triplicates and therefore we could not demonstrate its significance using statistical tests. This is possibly due to the endogenous ERK2 signaling already present in the cell lysates. Despite this difficulty, we found phosphorylation on the 154-162 amino acids of the peptide corresponding to the cell proliferation marker CDK1 (CDC2), to be significantly increased in embryo lysates overexpressing ERK2*** and FGF8. Direct interaction of active ERK2 with CDC2/CDK1 has not been demonstrated before, but both kinases are key players in cell cycle regulation and known to promote $\mathrm{G} 2 / \mathrm{M}$ transition and proliferation. In response to mitotic stimulation ERK2 is known to induce expression of cyclin $\mathrm{D}$, which binds and activates CDK4 and CDK6. In addition, activated ERK2 increased the expression of cyclin A, which binds to either CDK1 or CDK2 [31]. The cyclinA/B-CDK1 complex becomes fully functional after dephosphorylation of inhibitory Tyr15 and Thr14 residues and phosphorylation of
Thr161 on CDK1 by Cdk Activating Kinases (CAK) [32, 33]. The molecular mechanism connecting ERK2 and CAK, leading to increased Thr161 phosphorylation of CDK1, remains to be identified.

\section{Conclusion}

In this study, we have successfully constructed two constitutive active zebrafish ERK2 mutants $z E R K 2^{\text {L84P/S162D }}$ and zERK2 $2^{\text {L84P/S162D/D330N }}$ which continue to drive downstream signaling during growth factor deprivation in vitro and which are more potent to relay signals to the nucleus and induce target gene transcription in vivo. In addition, cell proliferation can be induced by $\mathrm{zERK} 2^{\mathrm{L} 84 \mathrm{P} / \mathrm{S} 162 \mathrm{D} / \mathrm{D} 330 \mathrm{~N}}$ as elevated ERK2 signals increase the phosphorylation of CDK1, a key protein involved in promoting cell cycle progression. Future research will be focusing on the possible long-term effect of constitutive ERK2 activation by developing transgenic zebrafish lines that drive constitutive active ERK2 isoforms under the 

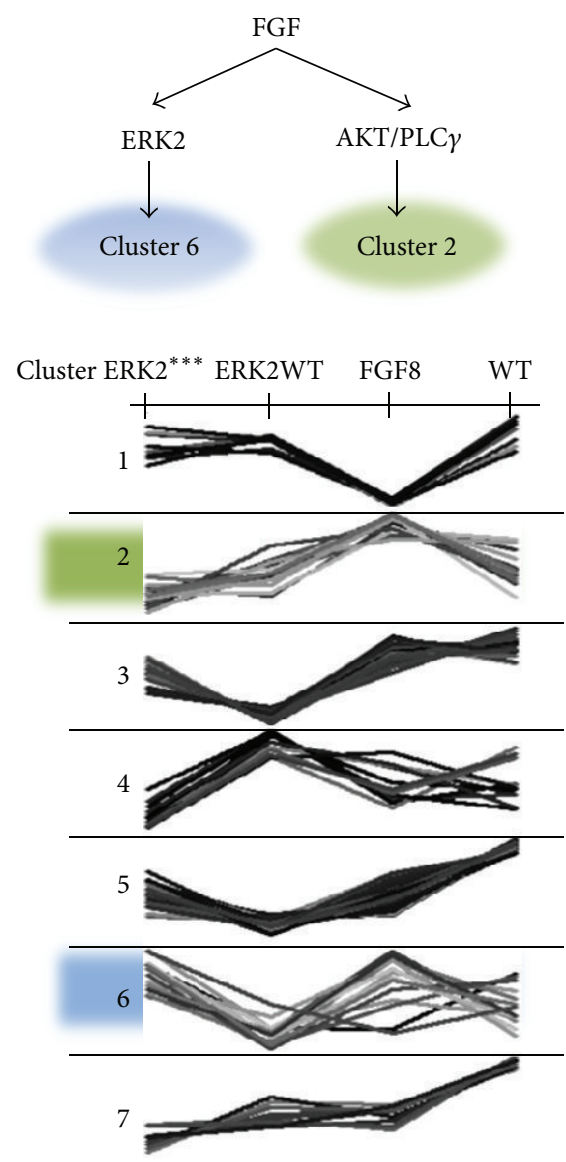

FIGURE 4: Kinome profile clustering of embryos ectopically expressing ERK2WT, ERK2 triple mutant, and FGF8. Simplified representation of FGF-ERK signalling pathways to downstream specific target clusters (up). Clusters are based on a Bionavigator-based clustering algorithm, which groups peptides into clusters according to treatment-based response similarities (down). AKT is Protein Kinase B (PKB), PLC $\gamma$ is Phospholipase C $\gamma$.

control of the melanocyte-specific promoters mitfa or kita. Analysis of the specific downstream molecular mechanisms that are involved in oncogenic transformation will attribute to the specific role of MAPK signaling, when compared to other systems such as the BRAF (BRAFV600E) transgenic fish line.

\section{Acknowledgments}

The authors thank Dr. Elizabeth Patton for providing the Tg(Dusp6:d2EGFP) zebrafish and Ulrike Nehrdich for excellent care of the fish. They thank also Riet Hilhorst of Pamgene for the kinome array data analysis. This work was financed by the EU Project ZF-Health (FP7-Health2009-242048) and ZF-Cancer (HEALTHF2-2008-201439). The COPAS system acquisition was in part supported by the Division for Earth and Life Sciences (ALW) with financial aid from The Netherlands Organization for Scientific Research (NWO, 834.10.004).

\section{References}

[1] J. A. McCubrey, L. S. Steelman, W. H. Chappell et al., "Roles of the Raf/MEK/ERK pathway in cell growth, malignant transformation and drug resistance," Biochimica et Biophysica Acta, vol. 1773, no. 8, pp. 1263-1284, 2007.

[2] P. J. Roberts and C. J. Der, "Targeting the Raf-MEK-ERK mitogen-activated protein kinase cascade for the treatment of cancer," Oncogene, vol. 26, no. 22, pp. 3291-3310, 2007.

[3] S. Yoon and R. Seger, "The extracellular signal-regulated kinase: multiple substrates regulate diverse cellular functions," Growth Factors, vol. 24, no. 1, pp. 21-44, 2006.

[4] A. Zebisch, A. P. Czernilofsky, G. Keri, J. Smigelskaite, H. Sill, and J. Troppmair, "Signaling through RAS-RAF-MEK-ERK: from basics to bedside," Current Medicinal Chemistry, vol. 14, no. 5, pp. 601-623, 2007.

[5] Z. Wei and H. T. Liu, "MAPK signal pathways in the regulation of cell proliferation in mammalian cells," Cell Research, vol. 12, no. 1, pp. 9-18, 2002.

[6] R. Hoshino, Y. Chatani, T. Yamori et al., "Constitutive activation of the $41-/ 43-\mathrm{kDa}$ mitogen-activated protein kinase signaling pathway in human tumors," Oncogene, vol. 18, no. 3, pp. 813822, 1999.

[7] N. Askari, R. Diskin, M. Avitzour, G. Yaakov, O. Livnah, and D. Engelberg, "MAP-quest: could we produce constitutively active variants of MAP kinases?" Molecular and Cellular Endocrinology, vol. 252, no. 1-2, pp. 231-240, 2006.

[8] S. J. Mansour, W. T. Matten, A. S. Hermann et al., "Transformation of mammalian cells by constitutively active MAP kinase kinase," Science, vol. 265, no. 5174, pp. 966-970, 1994.

[9] S. Cowley, H. Paterson, P. Kemp, and C. J. Marshall, "Activation of MAP kinase kinase is necessary and sufficient for PC12 differentiation and for transformation of NIH 3T3 cells," Cell, vol. 77, no. 6, pp. 841-852, 1994.

[10] W. Kolch, G. Heidecker, P. Lloyd, and U. R. Rapp, "Raf-1 protein kinase is required for growth of induced NIH/3T3 cells," Nature, vol. 349, no. 6308, pp. 426-428, 1991.

[11] F. A. Scholl, P. A. Dumesic, and P. A. Khavari, "Effects of active MEK1 expression in vivo," Cancer Letters, vol. 230, no. 1, pp. 1-5, 2005.

[12] M. Karasarides, A. Chiloeches, R. Hayward et al., "B-RAF is a therapeutic target in melanoma," Oncogene, vol. 23, no. 37, pp. 6292-6298, 2004.

[13] E. E. Patton, H. R. Widlund, J. L. Kutok et al., "BRAF mutations are sufficient to promote nevi formation and cooperate with p53 in the genesis of melanoma," Current Biology, vol. 15, no. 3, pp. 249-254, 2005.

[14] E. E. Patton and L. I. Zon, "Taking human cancer genes to the fish: a transgenic model of melanoma in zebrafish," Zebrafish, vol. 1, no. 4, pp. 363-368, 2005.

[15] J. F. Amatruda and E. E. Patton, "Genetic models of cancer in zebrafish," International Review of Cell and Molecular Biology, vol. 271, pp. 1-34, 2008.

[16] J. F. Amatruda, J. L. Shepard, H. M. Stern, and L. I. Zon, "Zebrafish as a cancer model system," Cancer Cell, vol. 1, no. 3, pp. 229-231, 2002.

[17] W. Goessling, T. E. North, and L. I. Zon, "New waves of discovery: modeling cancer in zebrafish," Journal of Clinical Oncology, vol. 25, no. 17, pp. 2473-2479, 2007.

[18] H. L. Siew, L. W. Yi, V. B. Vega et al., "Conservation of gene expression signatures between zebrafish and human liver 
tumors and tumor progression," Nature Biotechnology, vol. 24, no. 1, pp. 73-75, 2006.

[19] K. Stoletov and R. Klemke, "Catch of the day: zebrafish as a human cancer model," Oncogene, vol. 27, no. 33, pp. 4509-4520, 2008.

[20] D. E. Abbott, L.-M. Postovit, E. A. Seftor, N. V. Margaryan, R. E. B. Seftor, and M. J. C. Hendrix, "Exploiting the convergence of embryonic and tumorigenic signaling pathways to develop new therapeutic targets," Stem Cell Reviews, vol. 3, no. 1, pp. 68-78, 2007.

[21] M. J. C. Hendrix, E. A. Seftor, R. E. B. Seftor, J. KasemeierKulesa, P. M. Kulesa, and L.-M. Postovit, "Reprogramming metastatic tumour cells with embryonic microenvironments," Nature Reviews Cancer, vol. 7, no. 4, pp. 246-255, 2007.

[22] A. Moustakas and C.-H. Heldin, "Signaling networks guiding epithelial-mesenchymal transitions during embryogenesis and cancer progression," Cancer Science, vol. 98, no. 10, pp. 15121520, 2007.

[23] S. F. G. Krens, S. He, G. E. M. Lamers et al., "Distinct functions for ERK1 and ERK2 in cell migration processes during zebrafish gastrulation," Developmental Biology, vol. 319, no. 2, pp. 370383, 2008.

[24] M. A. Emrick, A. N. Hoofnagle, A. S. Miller, L. F. Ten Eyck, and N. G. Ahn, "Constitutive activation of extracellular signalregulated kinase 2 by synergistic point mutations," Journal of Biological Chemistry, vol. 276, no. 49, pp. 46469-46479, 2001.

[25] J. P. Hall, V. Cherkasova, E. Elion, M. C. Gustin, and E. Winter, "The osmoregulatory pathway represses mating pathway activity in Saccharomyces cerevisiae: isolation of a FUS3 mutant that is insensitive to the repression mechanism," Molecular and Cellular Biology, vol. 16, no. 12, pp. 6715-6723, 1996.

[26] D. Brunner, N. Oellers, J. Szabad, W. H. Biggs III, S. Lawrence Zipursky, and E. Hafen, "A gain-of-function mutation in Drosophila MAP kinase activates multiple receptor tyrosine kinase signaling pathways," Cell, vol. 76, no. 5, pp. 875-888, 1994.

[27] M. Tsang, S. Maegawa, A. Kiang, R. Habas, E. Weinberg, and I. B. Dawid, "A role for MKP3 in axial patterning of the zebrafish embryo," Development, vol. 131, no. 12, pp. 2769-2779, 2004.

[28] H. A. Harrington, M. Komorowski, M. Beguerisse-Diaz, G. M. Ratto, and M. P. Stumpf, "Mathematical modeling reveals the functional implications of the different nuclear shuttling rates of Erk1 and Erk2," Physical Biology, vol. 9, Article ID 036001, 2012.

[29] H. Shankaran, D. L. Ippolito, W. B. Chrisler et al., "Rapid and sustained nuclear-cytoplasmic ERK oscillations induced by epidermal growth factor," Molecular Systems Biology, vol. 5, article 332, 2009.

[30] G. A. Molina, S. C. Watkins, and M. Tsang, "Generation of FGF reporter transgenic zebrafish and their utility in chemical screens," BMC Developmental Biology, vol. 7, article 62, 2007.

[31] R. A. MacCorkle and T.-H. Tan, "Mitogen-activated protein kinases in cell-cycle control," Cell Biochemistry and Biophysics, vol. 43, no. 3, pp. 451-461, 2005.

[32] K. Coulonval, H. Kooken, and P. P. Roger, "Coupling of T161 and T14 phosphorylations protects cyclin B-CDK1 from premature activation," Molecular Biology of the Cell, vol. 22, no. 21, pp. 39713985, 2011.

[33] W. Krek and E. A. Nigg, "Cell cycle regulation of vertebrate p34cdc2 activity: identification of Thr161 as an essential in vivo phosphorylation site," The New Biologist, vol. 4, no. 4, pp. 323329, 1992. 

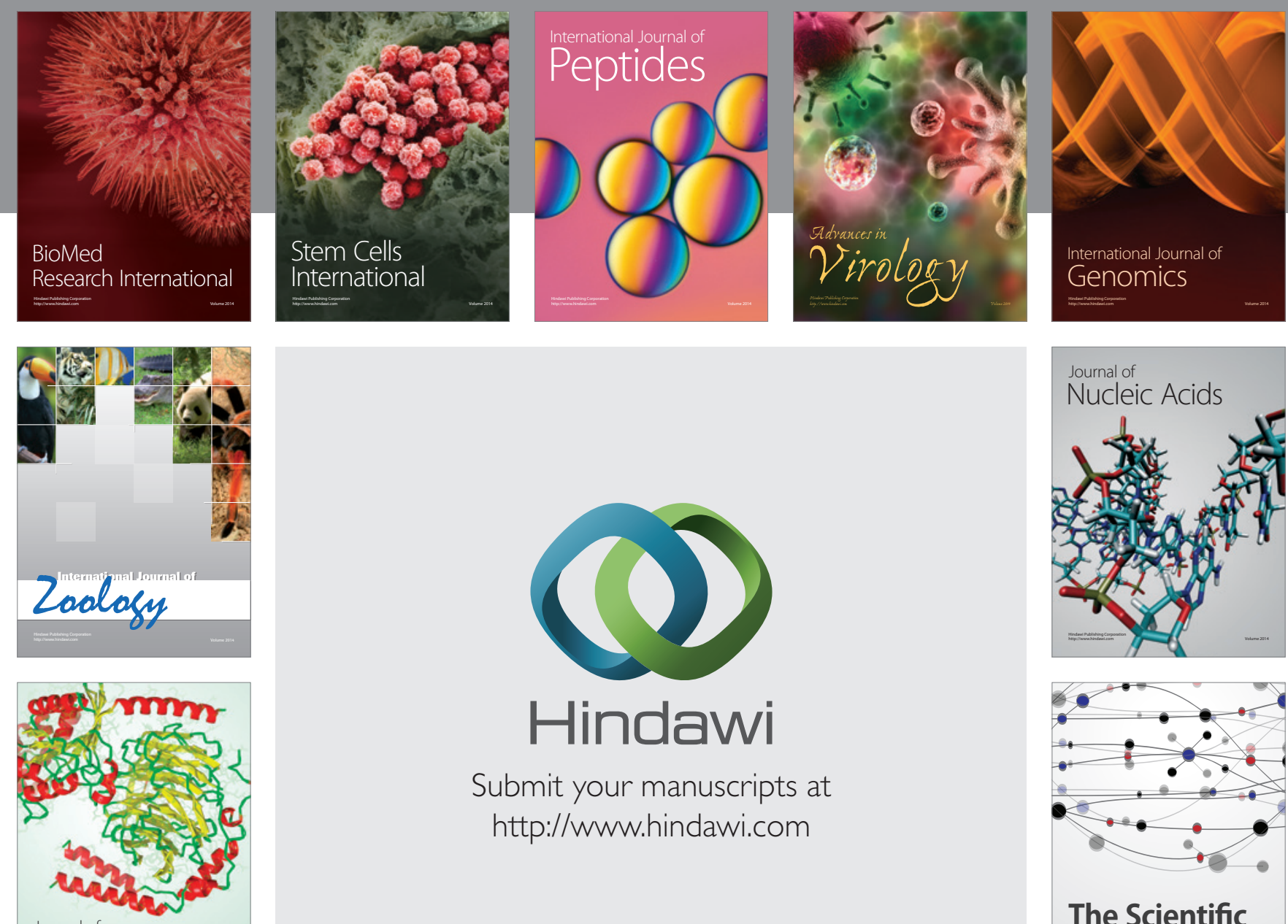

Submit your manuscripts at

http://www.hindawi.com

Journal of
Signal Transduction
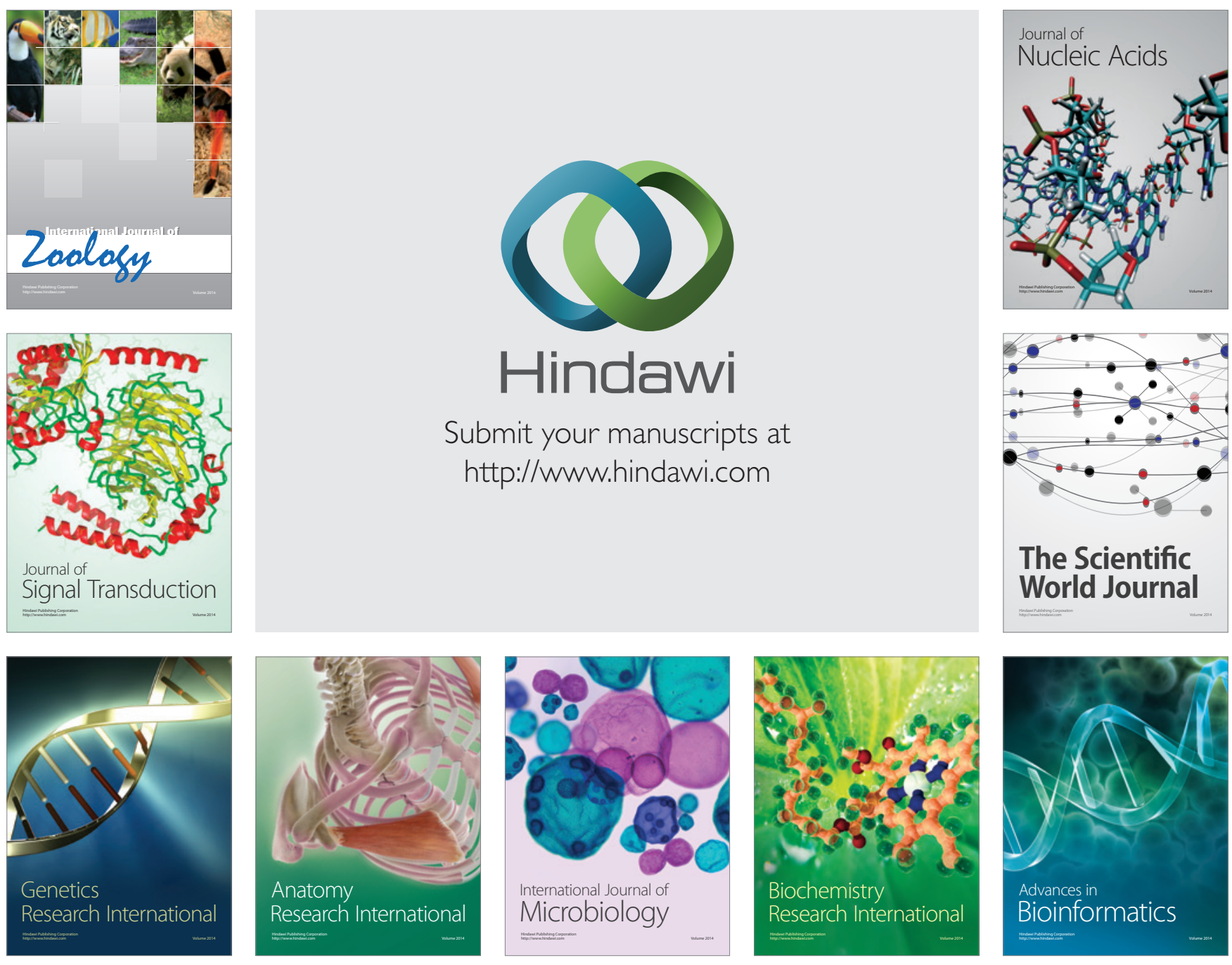

The Scientific World Journal
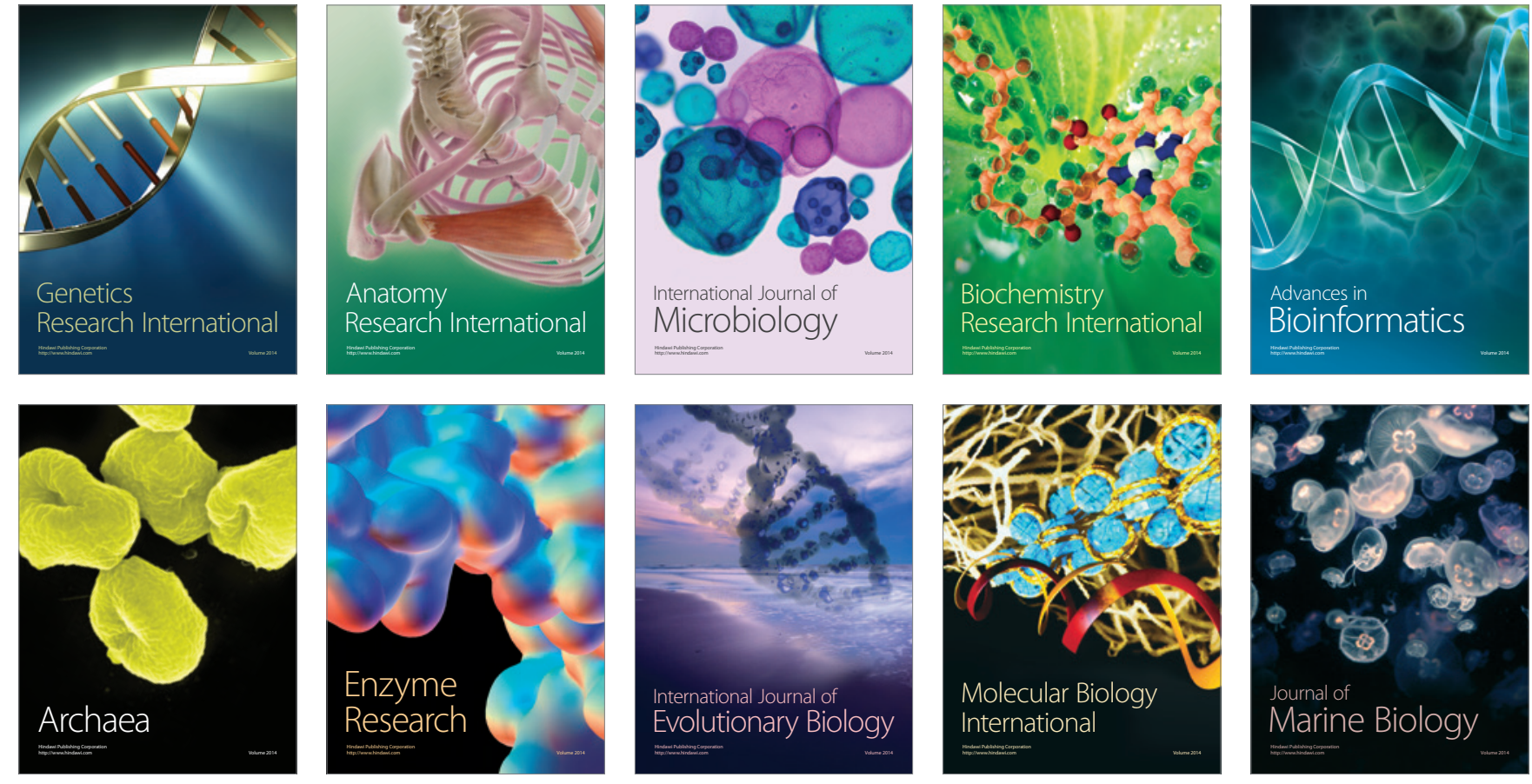